\title{
Molecular identification and functional analysis of Ctrp9 in Epinephelus coioides
}

\author{
Guokun Yang, Chaobin Qin ${ }^{\dagger}$, Bin Wang ${ }^{\ddagger}$, Jirong Jia, Xi Yuan, Caiyun Sun and \\ Wensheng Li
}

State Key Laboratory of Biocontrol, Institute of Aquatic Economic Animals and Guangdong Province Key Laboratory for Aquatic Economic Animals, South China Sea Bio-Resource Exploitation and Collaborative Innovation Center, Research Institute of Sun Yat-Sen University in Shen Zhen, School of Life Sciences, Sun Yat-Sen University, Guangzhou, People's Republic of China

${ }^{\dagger}$ (C Qin is now at College of Fisheries, Engineering Technology Research Center of Henan Province for Aquatic Animal Cultivation, Henan Normal University, Xinxiang, China)

₹(B Wang is now at Key Laboratory of Sustainable Development of Marine Fisheries, Ministry of Agriculture, Yellow Sea Fisheries Research Institute, Chinese Academy of Fishery Sciences,

Qingdao, China)

Correspondence should be addressed to $\mathrm{W} \mathrm{Li}$

Email

IssIws@mail.sysu.edu.cn

\begin{abstract}
CTRP9 is a member of the C1q/TNF-related protein (CTRP) superfamily and has been studied in mammals, whereas the comparative studies of CTRP9 in non-mammalian species are still absent. In this study, ctrp9 was isolated and characterized from the orange-spotted grouper (Epinephelus coioides). The full-length cDNA of ctrp9 was $1378 \mathrm{bp}$ in size with an ORF (open reading frame) of $1020 \mathrm{bp}$ that encodes a 339 amino acid pre-pro hormone. The mRNA expression of ctrp9 showed a rather high level in the kidney and brain, but a low level in other tissues. Furthermore, the mRNA expression of ctrp9 decreased significantly in the liver after fasting for 7 days and restored to the normal levels after refeeding. In contrast, the ctrp9 mRNA level increased in the hypothalamus after fasting. The recombinant gCtrp9 (globular Ctrp9) was prepared using the Pichia pastoris expression system and was verified by Western blot as well as mass spectrometry assays. In the primary hepatocytes culture, the recombinant gCtrp9 could inhibit the glucose production after 12-h treatment. After i.p. (intraperitoneal) injection with recombinant gCtrp9, in hypothalamus, mRNA expression levels of $n p y$ and orexin (orexigenic factors) decreased, whereas the expression levels of $c r h$ and pomc (anorexigenic factors) increased. Moreover, i.p. injection with the recombinant gCtrp9 could reduce the serum concentrations of glucose, TG and low-density lipoprotein cholesterol but increase the content of high-density lipoprotein cholesterol. Our studies for the first time unveil the structure of Ctrp9 and its potential role as a regulatory factor of metabolism and food intake in teleost.
\end{abstract}
Key Words
- Ctrp9
- food intake
- metabolism
- grouper

C) 2017 Society for Endocrinology Printed in Great Britain
Published by Bioscientifica Ltd.
Journal of Molecular

Endocrinology

(2017) 58, 179-191 


\section{Introduction}

Adipose tissue is not only an organ for energy storage but also an active endocrine organ (Scherer 2006). It can release a variety of cytokines, including adiponectin, resistin, leptin, IL (interleukin) 1B, IL6, TNFA (tumor necrosis factor $\alpha$ ), MCP1 (monocyte chemoattractant protein-1), adipsin and PAI1 (plasminogen activator inhibitor-1) (Trujillo \& Scherer 2006). It is well known that adiponectin is an important adipocytokine, which can improve insulin sensitization and can regulate glucose as well as lipid metabolism of the liver and muscle (Wong et al. 2009, Seldin et al. 2014). As the crucial cytokine, it has anti-atherogenic and anti-inflammatory properties and also protects against metabolic syndrome (Kadowaki et al. 2006, Esfahani et al. 2015). The C1q/TNFrelated proteins (CTRPs) are a highly conserved family of adiponectin paralogs, containing 15 members (Schaffler $\&$ Buechler 2012). Protein structure of CTRPs is similar to adiponectin, including an N-terminal signal peptide, a short variable domain, a collagen domain with variable numbers of Gly-X-Y repeat and a C-terminal globular domain. However, CTRP4 contains two globular domains (Wong et al. 2008, Peterson et al. 2012, Byerly et al. 2014). All the members' globular domains are homologous to those of the immune complement C1q, and their 3D structures show similarity to those of TNFA (Wong et al. 2008, Peterson et al. 2009). Moreover, CTRP9 can form heterotrimers, heterohexamers and hetero-oligomeric complexes with adiponectin (Peterson et al. 2009). Due to the highest homology to adiponectin, CTRP9 has similar functions as adiponectin in mammals.

A lot of studies show that Ctrp9 is a pluripotent factor in mammals. CTRP9 can induce vascular relaxation, protect against myocardial injury after ischemiareperfusion, alleviate cardiomyocyte apoptosis and fibrosis through adiponectin receptor 1/AMPK and PKA signaling pathway (Zheng et al. 2011, Kambara et al. 2012, 2015, Su et al. 2012, Sun et al. 2013). The lipid oxidation was enhanced in the muscle, and TG (triglyceride), insulin and serum glucose were decreased in the Ctrp9 transgenic mice (Peterson et al. 2013). The expression of orexigenic neuropeptides in hypothalamus was upregulated, and the levels of leptin and resistin were increased in mice lacking CTRP9 (Wei et al. 2014). Serum concentrations of CTRP9 had a positive correlation with arterial stiffness (Jung et al. 2014), and CTRP9 attenuated vascular smooth muscle cell proliferation and neointimal formation by increasing cAMP levels (Uemura et al. 2013). A recent study reported that gCTRP9 was the biologically active isoform that was digested in the necessary post-translational modification (Yuan et al. 2015).

The studies on CTRP9 are restricted to mammals, and the comparative aspects of CTRP9 in non-mammalian species, especially in lower vertebrates, are still unclear. To date, the function of Ctrp9 has never been reported in teleost. As the first step to investigate the functional roles of Ctrp9 in teleost, we isolate and characterize the gene of ctrp9 in the orange-spotted grouper (Epinephelus coioides). The recombinant protein of gCtrp9 was prepared by using Pichia pastoris system, and the roles of gCtrp9 in the regulation of energy metabolism and food intake were evaluated. To the best of our knowledge, this is the first report about CTRP9 in non-mammalian vertebrates.

\section{Materials and methods}

\section{Animals}

All of the animal experiments were approved by the Animal Care Committee of Sun Yat-Sen University. For the tissue distribution experiments and hepatocytes isolation experiments, approximately two-year-old female orangespotted groupers (Epinephelus coioides) with a body weight of 550-650g were purchased from the Huangsha aquatic products wholesale market in Guangzhou, China. The fish were acclimated to indoor tanks with recirculating seawater at room temperature under a cyclic light-darkness photoperiod (12h:12h) for at least one week. During the acclimation period, the fish were fed commercial pellets daily until satiety as described previously (Wang et al. 2014). All the animal experiments were carried out in accordance with the guidelines and approval from the Sun Yat-Sen University Animal Care and Use Committee.

\section{Molecular cloning of grouper ctrp9}

Molecular cloning of ctrp9 was conducted in grouper by nested PCR coupled to $3^{\prime} / 5^{\prime}$ RACE according to the procedures described previously (Qin et al. 2014). The first-strand cDNA was synthesized using the M-MLV kit (Invitrogen). Using primers (Table 1) designed based on the conserved regions of ORF of fugu rubripe, medaka, three-spined stickleback and spotted green pufferfish ctrp9, nested PCR was performed and a partial fragment of grouper ctrp 9 cDNA was isolated. Based on the nucleotide sequence obtained, new primers were synthesized and used in $3^{\prime} / 5^{\prime}$ RACE (Table 1 ). To confirm the composite ORF sequence, RT-PCR was performed using a pair of

Published by Bioscientifica Ltd. 
Table 1 Primers used in this study.

\begin{tabular}{|c|c|c|}
\hline Name & Sequences $\left(5^{\prime}-3^{\prime}\right)$ & Purpose \\
\hline Partial CDS-F1 & CCYGGAATACCAGGRGACCC & Partial CDS clone \\
\hline Partial CDS-F2 & CCHGGRAAAATGGGVCCCCA & \\
\hline Partial CDS-R1 & AAGACRGTGATGTGRTAGGTRAAG & \\
\hline Partial CDS-R2 & ACYTGCAGCCASACCTTGTC & \\
\hline 3'RACE-F1 & GAAGTTGGCCTTAGAGGTGACAGA & $3^{\prime}$ RACE \\
\hline 3'RACE-F2 & CTCACAGCACAAAGTAAACTCCCTA & \\
\hline 3'RACE-F3 & GCGGGAGCATATTTCTTCACCTAC & \\
\hline 5'RACE-R1 & TAGGGAGTTTACTTTGTGCTGTGAG & 5'RACE \\
\hline 5'RACE-R2 & ATATTGCCTTTGTGACCTGGAAC & \\
\hline 5'RACE-R3 & GGTCCAGGCAGCCCAAGAT & \\
\hline ORF-F & TTTTGCATTGTTGATAGATAGG & ORF clone \\
\hline ORF-R & AGACAGGCTGATTTCTTATGAC & \\
\hline ctrp9-RT-F & CTTAGAGGTGACAGAGGCATTC & ctrp9 real-time PCR \\
\hline ctrp9-RT-R & CTGTGGATCGTAGTGATTCTGC & \\
\hline$n p y-\mathrm{RT}-\mathrm{F}$ & ACGCTCCCACAGTCAAGATAC & npy real-time PCR \\
\hline npy-RT-R & GCGGCTCATAGAGGTAAAGG & \\
\hline orexin-RT-F & TGTTGCTTTGTCGCTCTGG & orexin real-time PCR \\
\hline orexin-RT-R & TCTTCAGTCCTCTTGCCCAT & \\
\hline pomc-RT-F & TCCCAGGCGACAACCAC & pomc real-time PCR \\
\hline pomc-RT-R & TCGGCTGACTCTTCTTCTAC & \\
\hline crh-RT-F & TACATCTACCAAGGTCCCA & crh real-time PCR \\
\hline crh-RT-R & CAGAGGCAGCAGCACTA & \\
\hline $18 \mathrm{~S}-\mathrm{F}$ & CCTGAGAAACGGCTACCACATCC & Reference gene \\
\hline $18 S-R$ & AGCAATTTAGTATACGCTATTGGAG & \\
\hline AP & GGCCACGCGTCGACTAGTAC(T) 16 & Universal primers \\
\hline AAP & GGCCACGCGTCGACTAGTACGGGGGGGGGG & \\
\hline AUAP & GGCCACGCGTCGACTAGTAC & \\
\hline rgCtrp9-F & CGGAATTCCATCATCATCATCATCATCTTGTTATCTCTAAAAGCGCTCTAAAAGCG & Expression gCtrp9 \\
\hline rgCtrp9-R & ATAGTTTAGCGGCCGCCTAAGCCCCAAAGATTA & \\
\hline
\end{tabular}

Degenerate bases: $Y=C+T ; R=A+G ; H=A+T+C ; V=A+G+C ; S=C+G$.

gene-specific primers designed at the upstream and downstream of protein coding sequence. The following procedure was used for performing all PCRs: $94^{\circ} \mathrm{C}, 3 \mathrm{~min}$; $94^{\circ} \mathrm{C}, 30 \mathrm{~s}, 50-62^{\circ} \mathrm{C}, 30 \mathrm{~s}, 72^{\circ} \mathrm{C}, 1-1.5 \mathrm{~min}, 35$ cycles; $72^{\circ} \mathrm{C}$, $10 \mathrm{~min}$. All the PCR products were purified by the E.Z.N.A Gel Extraction Kit (OMEGA, bio-tek) and subcloned into pCR2.1 vector (Invitrogen) for DNA sequencing. The ORF finder in NCBI (http://www.ncbi.nlm.nih.gov/gorf/orfig. cgi) was used to get the ORF, and the molecular mass and isoelectric point of Ctrp9 precursor protein were analyzed with ExPASy (http://web.expasy.org/compute_pi/). The signal peptide of Ctrp9 was predicted using the SignalP4.1 Server (http://www.cbs.dtu.dk/services/SignalP/). The phosphorylation and glycosylation sites of the Ctrp9 pre-pro hormone were analyzed by NetPhos 2.0 Server (http://www.cbs.dtu.dk/services/NetPhos/) and NetNGlyc 1.0 Server (http://www.cbs.dtu.dk/services/NetNGlyc/), respectively. Sequence alignment at the protein level was performed using ClustalW2 (http://www.ebi.ac.uk/Tools/ $\mathrm{msa} /$ clustalw2/). The phylogenetic tree was constructed with MEGA6.0 by neighbor-joining method (bootstrap phylogeny test, 2000 replicates).

\section{Tissue distribution and effects of nutritional status on} ctrp9 mRNA expression

Three two-year-old female groupers were anesthetized by MS222 and decapitated for tissue distribution. Various tissue samples were collected quickly and snap-frozen in liquid nitrogen, and then stored in $-80^{\circ} \mathrm{C}$ until RNA extraction.

Juvenile fish with a body weight of 55-65 $\mathrm{g}$ and body length of $13-14 \mathrm{~cm}$ were used in the fasting and refeeding experiment as described previously (Qin et al. 2014). After acclimation for 1 week, all fish were divided into 3 groups ( $n=6$ fish/group). The first group of fish was fed for 7 days (fed $6 \mathrm{~h}$ before sampling on Day 7) and used as the control group ('Fed'), the second group of fish was maintained under food deprivation for 7 days ('Fasted') and the third group of fish was fasted for 7 days and refed $6 \mathrm{~h}$ before sampling on Day 7 ('Refed'). At the end of the experiments, all fish were anesthetized by MS222 and decapitated. The liver, adipose tissue, muscle and hypothalamus samples were collected quickly and snap-frozen in liquid nitrogen and then stored in $-80^{\circ} \mathrm{C}$ until RNA extraction.

Published by Bioscientifica Ltd. 


\section{RNA extraction, reverse transcription and real-time quantitative PCR}

All experiments were performed according to the standard procedures established in our lab (Wang et al. 2015a). Briefly, total RNA was extracted from tissues using TRIzol reagent (Invitrogen) according to the manufacturer's instruction. The purity and yield of RNA were assessed by a NanoDrop 2000C spectrophotometer (Thermo Scientific) with OD260: 280 ratios between 1.8 and 2.0. Two micrograms of total RNA was incubated with RNasefree DNase-I (NEB, USA) at $37^{\circ} \mathrm{C}$ for $10 \mathrm{~min}$ to eliminate contaminating genomic DNA and then treated with $5 \mathrm{mM}$ EDTA at $75^{\circ} \mathrm{C}$ for $10 \mathrm{~min}$ to inactivate DNase-I. The first-strand cDNA was synthesized with M-MLV Reverse Transcriptase (Invitrogen) according to the manufacturer's protocol. The gene expression levels were determined with real-time quantitative PCR. A total of $10 \mu \mathrm{L}$ of the PCR reaction volume contained $5 \mu \mathrm{L}$ of Thunderbird SYBR Green qPCR Mix (TOYOBO, Japan), $0.3 \mu \mathrm{L}$ of forward and reverse primers $(10 \mu \mathrm{M}$ each $), 1 \mu \mathrm{L}$ of diluted cDNA templates and $3.4 \mu \mathrm{L}$ of water. Amplification of samples was carried out with the Roche LightCycler 480 Realtime PCR Detection System using the following thermal cycling profiles: $95^{\circ} \mathrm{C}$ for $1 \mathrm{~min}, 40$ cycles of $95^{\circ} \mathrm{C}$ for $15 \mathrm{~s}$, $56^{\circ} \mathrm{C}$ for $15 \mathrm{~s}$ and $72^{\circ} \mathrm{C}$ for $30 \mathrm{~s}$. The $18 \mathrm{~S}$ gene was used as the internal reference, and the $18 \mathrm{~S}$ levels remained stable between various treatments throughout the study. The relative gene expression levels were normalized to the $18 \mathrm{~S}$ levels and were calculated by the comparative Ct method (Schmittgen \& Livak 2008).

\section{Production of recombinant protein by Pichia pastoris}

Recombinant global Ctrp9 (gCtrp9) was obtained by Pichia pastoris as described previously (Chen et al. 2012). The cDNA fragment coding globular domain of ctrp9 was cloned from pCR2.1-ctrp9 vector by PCR with specific primers. EcoRI and NotI sites were introduced at the upstream and downstream ends of the fragment, respectively. Moreover, a $6 \times$ HIS tag was introduced to the site between the EcoRI site and N-terminal sequence of gCtrp9. The primer sequences were shown in Table 1. The sequence was inserted to form an in-frame fusion peptide with the $\alpha$-factor secretion signal of pPICZ $\alpha \mathrm{A}$ and the KEX2 cleavage site. The cloned fragment was digested with restriction enzymes (EcoRI and NotI; NEB), purified and subcloned into pPICZ $\alpha$ A (Invitrogen) (Supplementary Fig. 1 for details, see section on supplementary data given at the end of this article). The recombinant plasmid was transformed into E. coli $\mathrm{DH} 5 \alpha$ and selected on LB low-salt Zeocin plate (Invitrogen). The positive clones were sequenced by ABI 3730 DNA sequencer (Applied Biosystems).

The expression plasmid was linearized by Sac I (NEB) and transformed into Pichia pastoris X-33 (Invitrogen) by electroporation according to manufacturer's protocol (Invitrogen, 2008) and selected on YPDS (1\% yeast extract, $2 \%$ peptone, 2\% agar, 20\% glucose and $0.1 \mathrm{M}$ D-sorbitol) containing Zeocin $(250 \mu \mathrm{g} / \mathrm{mL})$. After incubation of $60 \mathrm{~h}$ at $28^{\circ} \mathrm{C}$, the clones were picked, and the expression condition was optimized. The procedure of expression was as follows: single clone was grown in $10 \mathrm{~mL}$ BMGY medium (1\% yeast extract, $2 \%$ peptone, $1 \%$ glycerol, $1.34 \%$ yeast nitrogen base w/o amino acid, $10 \mathrm{mM} \mathrm{K}_{2} \mathrm{HPO}_{4}, 100 \mathrm{mM}$ $\mathrm{KH}_{2} \mathrm{PO}_{4}$ and $0.4 \mathrm{mg} / \mathrm{L}$ biotin), 200 r.p.m shaking $18-24 \mathrm{~h}$ at $28^{\circ} \mathrm{C}$, centrifuged and resuspended in $100 \mathrm{~mL}$ BMGY. After shaking $200 \mathrm{rpm}$ for $18-24 \mathrm{~h}$ at $28^{\circ} \mathrm{C}$, the cells were centrifugated and resuspended in $100 \mathrm{~mL}$ BMMY $(1 \%$ yeast extract, $2 \%$ peptone, $0.5 \%$ methanol, $1.34 \%$ yeast nitrogen base w/o amino acid, $10 \mathrm{mM} \mathrm{K}_{2} \mathrm{HPO}_{4}, 100 \mathrm{mM}$ $\mathrm{KH}_{2} \mathrm{PO}_{4}$ and $0.4 \mathrm{mg} / \mathrm{L}$ biotin), and TWEEN-80 (Sigma) was added to a final concentration of $0.4 \%$. After shaking at $200 \mathrm{rpm}$ for $18-24 \mathrm{~h}$ at $28^{\circ} \mathrm{C}$, the suspension was added with $100 \%$ methanol to a final concentration of $0.5 \%$. After shaking at $200 \mathrm{rpm}$ for $18-24 \mathrm{~h}$ at $28^{\circ} \mathrm{C}$, culture media were centrifuged and the harvested supernatant were loaded onto a $1 \mathrm{~mL} \mathrm{Ni}{ }^{+-} \mathrm{NTA}$ resin column (GE, USA). The recombinant gCtrp9 was eluted with $150 \mathrm{mM}$ imidazole. Purified proteins were dialyzed against PBS buffer. The purified protein was analyzed by SDS-PAGE, Western blot and mass spectrometry. The protein concentrations were quantified using BCA assay (Beyotime, China).

\section{Hepatocyte isolation, culture and treatments}

Hepatocytes were prepared by collagenase IV/DNase II digestion method and seeded in 24-well culture plates at a density of $5 \times 10^{5}$ cells/well in $1 \mathrm{~mL}$ of L15 medium with $10 \%$ FBS (fetal calf serum) at $25^{\circ} \mathrm{C}$ and saturated humidity with plain air in an incubator as described previously (Wang et al. 2015a). After overnight incubation, the medium was gently changed to serum-free fresh L15 medium (no phenol red), and the cell cultures were incubated for $1 \mathrm{~h}$ before adding recombinant gCtrp9 $(10 \mu \mathrm{g} / \mathrm{mL})$ for $6-$ and $12-\mathrm{h}$ treatments. At the end of the incubation, the supernatant was collected for the measurement of glucose concentration using the glucose assay kit (Robio, China), and the cells were lysed by RIPA (Beyotime), and the protein content was measured

Published by Bioscientifica Ltd. 
by BCA assay for correcting for cell number variations (Wei et al. 2011).

\section{I.p. injection of the recombinant gCtrp9}

For in vivo experiments, female fish with an average length of 9-11 cm and weight of 35-45 $\mathrm{g}$ were maintained in a 12-h/12-h light/darkness cycle and fed twice daily at least one week before the experiment. The recombinant gCtrp9 was injected intraperitoneally at concentrations of 0.5 and $5 \mu \mathrm{g} / \mathrm{g}$ B.W. (body weight). For the control groups, fish were injected with PBS based on the body weight. Blood samples were collected from the caudal vein of each fish after gCtrp9 injection for 3, 6 and $12 \mathrm{~h}$ ( $n=12$ for each group). These blood samples were transferred to sterile centrifuge tubes and incubated at room temperature at least for $30 \mathrm{~min}$. Then, the samples were centrifuged at $7500 \mathrm{~g}$ for $10 \mathrm{~min}$, and the serum was isolated. The serum was stored at $-80^{\circ} \mathrm{C}$ for the determination of glucose (GLU), triacylglycerol (TG), high-density lipoprotein cholesterol (HDL-C) and low-density lipoprotein cholesterol (LDL-C). The 239

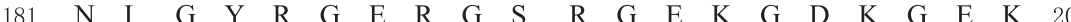
719 GGA GAA GAA CTT GTT ATC TCT AAA AGC GCC TTC TCA GTG GGA CTC ACA GCA CAA AGT AAA 778

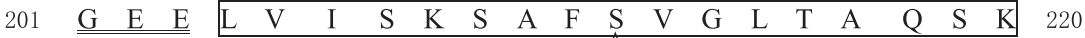
779 CTC CCT ACA CCT AAT GCT CCG ATC CGG TTT GAC AAG ATC ATT TAC AAT GTG CAG AAT CAC 838

$\begin{array}{llllllllllllllllllllllll}221 & \mathrm{~L} & \mathrm{P} & \mathrm{T} & \mathrm{P} & \mathrm{N} & \mathrm{A} & \mathrm{P} & \mathrm{I} & \mathrm{R} & \mathrm{F} & \mathrm{D} & \mathrm{K} & \mathrm{I} & \mathrm{I} & \mathrm{Y} & \mathrm{N} & \mathrm{V} & \mathrm{Q} & \mathrm{N} & \mathrm{H} & 240\end{array}$

839 TAC GAT CCA CAG ACA GGA AGA TTC ACA TGC TCC GCA GCG GGA GCA TAT TTC TTC ACC TAC 898

\begin{tabular}{l|llllllllllllllllllllll}
241 & Y & D & P & Q & T & G & R & F & T & C & S & A & A & G & A & Y & F & F & T & Y & 260
\end{tabular}

899 CAC ATC ACA GTC TTC TCC CGG AAC GTG AAG GTT GCT CTG GTG AAG AAT GGT GCA AAG ATC 958 $\begin{array}{lllllllllllllllllllllll}261 & \mathrm{H} & \mathrm{I} & \mathrm{T} & \mathrm{V} & \mathrm{F} & \mathrm{S} & \mathrm{R} & \mathrm{N} & \mathrm{V} & \mathrm{K} & \mathrm{V} & \mathrm{A} & \mathrm{L} & \mathrm{V} & \mathrm{K} & \mathrm{N} & \mathrm{G} & \mathrm{A} & \mathrm{K} & \mathrm{I} & 280\end{array}$

959 ATT CAC ACC ACG GAT AAC TAC CAG AGC AGC GAG GAT CAG GCA GCA GGG GGC GCT GTG CTG 1018 $\begin{array}{lllllllllllllllllllllll}281 & \mathrm{I} & \mathrm{H} & \mathrm{T} & \mathrm{T} & \mathrm{D} & \mathrm{N} & \mathrm{Y} & \mathrm{Q} & \mathrm{S} & \mathrm{S} & \mathrm{E} & \mathrm{D} & \mathrm{Q} & \mathrm{A} & \mathrm{A} & \mathrm{G} & \mathrm{G} & \mathrm{A} & \mathrm{V} & \mathrm{L} & 300\end{array}$ 1019 AAC CTG GAT GTG GGA GAC AAG GTG TGG CTG CAG GTG ACT GGG GGA GAG CTG TAC AAT GGG 1078 $\begin{array}{llllllllllllllllllllll}301 & \text { N } & \text { L } & \text { D } & \text { V } & \text { G } & \text { D } & \text { K } & \text { V } & \text { W } & \text { L } & \text { Q } & \text { V } & \text { T } & \text { G } & \text { G } & \text { E } & \text { L } & \text { Y } & \text { N } & \text { G } & 320\end{array}$ 1079 CTC TTT GCT GAT GAA GAT GAT GAC ACG ACC TTC TCT GGG TTC TTA ATC TTT GGG GCT TAG 1138

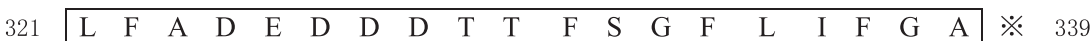
1139 atgaggcaaactttctttataattgatgttgaatattctaagaatagaaatgagtcataagaaatcagcetgtctct 1217 1218 aaactttggttgactacataatgcaatgtacagtgtacctaagtacatttactcacctactgtactaaagaacaaattt 1296 1297 gaggtacttgtaccttaattaagtattcaattttattctacttaaatacttatactcaaatcataaaaaaaaaaaaa 1375 1376 aaa

\section{Figure 1}

The cDNA and deduced amino acids of grouper ctrp9. Single underline represented signal peptide; dotted line represented variable domain; double underline represented collagenous domain and box represented domain of globular. The asterisk represented the stop codon. The gray shadow showed predicted glycosylation site, and the trilaterals showed predicted phosphorylation sites. 
concentrations of GLU, TG, HDL-C and LDL-C were measured with commercial kits (Jiancheng, China). Then, the fish were killed by decapitation. The hypothalamus was separated quickly and snap-frozen in liquid nitrogen.

\section{Statistical analysis}

All data were shown as mean \pm S.E.M., and statistical analysis was performed with SPSS 18.0 software (SPSS). The significant differences were identified by one-way ANOVA using Fisher's least significance difference (LSD) test. A probability of less than $0.05(P<0.05)$ was considered as a significant difference.

\section{Results}

\section{Molecular cloning and sequence analysis of grouper ctrp9 cDNA}

Using 3'/5' RACE coupled to nested PCR, the full-length cDNA of grouper ctrp9 was isolated. The $\operatorname{ctrp} 9$ cDNA was $1378 \mathrm{bp}$ in size with a $118 \mathrm{bp} 5^{\prime} \mathrm{UTR}$ and $240 \mathrm{bp} 3^{\prime} \mathrm{UTR}$. The ORF of $1020 \mathrm{bp}$ encoding 339 amino acids precursor with a deduced molecular mass of $35.0964 \mathrm{kDa}$ and isoelectric point of 8.76, respectively (Fig. 1). Based on sequence analysis using SignalP program, the first 22 amino acids were predicted to be the signal peptide. Ctrp9 consisted of three domains, including the variable domain (10 amino acids), the collagenous domain (171 amino acids) containing 57 Gly-X-Y elements, and the globular domain (136 amino acids). The globular domain was namely the functional domain (Fig. 1). Seven phosphorylation sites were predicted in the grouper Ctrp9 precursor by NetPhos including four serine residues, two threonine residues and one tyrosine residue. Furthermore, there was one $\mathrm{N}$-glycosylation site (NGT) in the grouper Ctrp9 protein predicted by NetNGlyc (Fig. 1). The amino acid sequence similarities were aligned between grouper Ctrp9 and other species using ClustalW2 program (Fig. 2). As shown in Table 2, the grouper Ctrp9 precursor displayed a high degree of identity with other fish Ctrp9 precursors and a low degree of identity with mammals and birds (less than $60 \%$ ). The identity of globular domain of Ctrp9 in groupers showed a higher degree of identity with other species. The phylogenetic tree was constructed using MEGA 6.0 based on Ctrp9 amino acid sequences of grouper and other species. The phylogenetic tree formed two distinct clusters (Fig. 3). Grouper Ctrp9 clustered

\section{Larimichthys crocea centrarchus labrax pinephelus coioides Oreochromis nilotic Takifugu rubripes Cynoglossus semilae Oryzias latipes Danio rerio Gallus gallus
Alligator sinensi Homo sapiens Mus musculus}

Larimichthys crocea Dicentrarchus labrax Epinephelus coioides Oreochromis niloticus Takifugu rubripes Cynoglossus semilaevis Oryzias latipes

Danio rerio

Gallus gallus Alligator sinensis Homo sapiens Mus musculus

Larimichthys crocea Dicentrarchus labra Epinephelus coioides Oreochromis niloticus Takifugu rubripes Cynoglossus semilaevis Oryzias latipes

Danio rerio

Gallus gallus Alligator sinensis Homo sapiens Mus musculus

Larimichthys crocea Dicentrarchus labrax Epinephelus coioides Oreochromis niloticus Takifugu rubripes Cynoglossus semilaevis Oryzias latipes

Danio rerio

Gallus gallus Alligator sinensis Homo sapiens Mus musculus

Larimichthys crocea Dicentrarchus labrax Epinephelus coioides Oreochromis niloticus Takifugu rubripes Cynoglossus semilaevis Oryzias latipes

Danio rerio Gallus gallus Alligator sinensis Homo sapiens Mus musculus

Larimichthys crocea Dicentrarchus labrax Epinephelus coioides Oreochromis niloticus Takifugu rubripes Cynoglossus semilaevis Oryzias latipes Danio rerio Gallus gallus Alligator sinensi Homo sapiens

\section{Figure 2}

Amino acid sequence alignment of Epinephelus coioides Ctrp9 with other species. Homo sapiens (NP_848635.2), Mus musculus (NP_898998.2), Gallus gallus (XP_001234806.2), Alligator sinensis (XP_006017705.1), Danio rerio (XP_005162770.1), Oreochromis niloticus (XP_005471911.1), Takifugu rubripes (XP_003968015.2), Larimichthys crocea (XP_010736742.1), Dicentrarchus labrax (embICBN81948.1), Cynoglossus semilaevis (XP_008306029.1) and Oryzias latipes (XP_004081095.1).

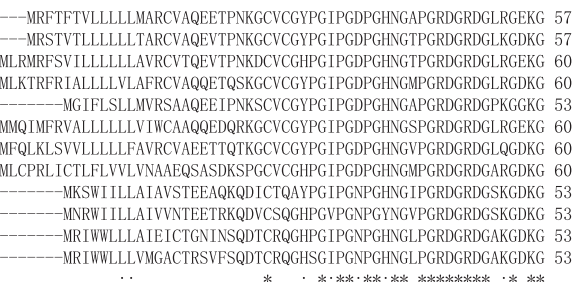

DQ--GDIGPTGRAGUDGHRGEKGETGAVGPAGLKGKRGDDGERGPPGKMGPQGVQGPIGL 115 DQ--GQVGPVGAAGNDGHRGDKGEPGAVGPAGLKGKRGENGERGPPGKMGPQGVQGPIGL 11 DQ-DQ GEFG TGPGGLNGQKGDKGELGTVGPAGLKGKRGENGELGHPGKMGPQGIQGPMGL 11 TK-DR--GTCGDO DGHREKGEPGINGAGAKGKKGDDGERGPGNG QGVQP 118 DTVLCG DT--GYLPGAKDAGERQRGANGE DA--GEPGRPGSPGKDGTSGEKGERGADGKVEAKGIKGDQGSRGSPGKHGPKGLAGPMGE 111 DA--GEPGHPGGPGKDGIRGEKGEPGADGRVEAKGIKGDPGSRGSPGKHGPKGSIGPTGE 11

KGNKGELGLPGPQGSKGDLGPPGPEGPKGEIGLRGDRGIQGPLGPIGRPGPKGEIGVPGH 175 KGNKGELGLPGPQGPKGDLGPPGPEGPKGEIGLRGDRG IQGPLGPPGRPGPKGEIGVPGH 175 KGSKGDLGLPGPQGPKGDLGPLGPQGPKGEVGLRGDRG IQGPLGPPGRPGPKGEIGVPGH 178 KGNKGELGLPGPPGPEGHLGPPGPQGEKGETGLRGDRGIPGPLGPPGRPGPKGDMGFPGN 178 KGNEGEIGLPGLQGPKGELGPPGPVGLKGETGLRGDRGIPGPPGPPGRAGPKGEIGVPGH 171 KGNKGELGLPGPQGIKGDFGPTGPQGQKGETGLQGDRGTQGPLGSPGRPGPKGDIGVPGH 178 KGQKGELGIPGPQGIKGDVGPVGPEGPQGDIGNKGDKGIQGPLGPPGRPGPKGEIGQPGN 175 KGQKGELGLQGQKGLKGDIGPLGPKGTKGEIGHPGIIGLPGPVGPIGNPGPKGNTGDLGP 173 KGQKGEIGLQGQKGIKGDIGPMGPKGMKGEIGNPGEIGLPGPVGPIGNPGPEGSVGGPGP 171 KGLRGETGPQGQKGNKGDVGPTGPEGPRGNIGPLGPTGLPGPUGPIGKPGPKGEAGPTGP 171 QGLPGETGPQGQKGDKGEVGPTGPEGLMGSTGPLGPKGLPGPMGPIGKPGPRGEAGPMGP 171

KGNIGYRGDRGSRGEKGDRGEKGDAFVISKSAFSVGLTAVSKLPAANGPIRFDKIIYNQQ 235 KGNIGYRGDRGTRGEKGDKGEKGDALVIAKSAFSVGLTAQSKLPAANAPIRFDRIIYNQQ 235 KGNIGYRGERGSRGEKGDKGEKGEELVISKSAFSVGLTAQSKLPTPNAPIRFDKIIYNVQ 238 KGNIGYRGDRGARGEKGDRGEKGDEFVISKSAFSVGLTTQTKLPAANAPIRFDKIIYNEQ 238 KGNGGRGEKGDEGVKGEKGEKGDASVVSKSAFTVGLTAQSKLPAANGPIRFDKIIYNQQ 231 KGSIGYRGERGNRGEKGDKGEKGDAAVTSNSAFSVGLTAQTKLPAANAPIRFDRIIYNQQ 238 KGNIGYRGERGARGEKGSKGDKGDSPLIPKSAFTVGLTAQTKLPATNSPIRFDKITYNAQ 238 KGSIGVRGERGSKGDMGEQGPKGDMPEIPKSAFSARLSDSTKLPAANAP IRFDRVLYNSQ 235 PGSPGIQGERGLKGIRGDKGNTGAPAVLPRSAFSVGLTAATKFPPHSHPIKFDKVLYNGL 233 KGNPGQGEKGWKGDRGDKGNTGDTPVVPRSAFSVGLTAETKFPPANRPIKFDKVLYNGL 231 QGLPGVGIRGWKGDRGEKGKIGETLVLPKSAFTVGLTVLSKFPSSDMPIKFDKILYNEF 231 QGEPGVRGWRGWKGDRGEKGKVGEAPLVPKSAFTVGLTVISKFPPPDAPIKFDKILYNEL 23

NHYSPQTGRFTCSAAGAYFFTYHITVFSRNVKVALVKNGAKVIHTTDNYQSSEDQAAGGA 295 NHYDPQTGRFTCSAAGAYFFTYHITVFSRNVKVALVKNGAKIIHTTDNYQSSEDQAAGGA 298 NIYDPQTGRFTCSAAGAYFFTYHITVFSRNVKVALVKNGAKI IHTTDNYQGSEDQAAGGA 298 NHYDPQTGRFTCSVAGAYFFTYHITVFSRNVKVALTKNGEKLIHTTDSYQSSEDQATGGA 291 NHYDPTGRFTCSVAGTYYFTYHITVYSRNVKVVLMKNGAKIIHTMDNYQSSEDQAAGGT 298 MYDPLTGRFTCSEAGVYYFTYHITVFSKNVKVALMKNGAKILHTTDNYQSSEDQASGGA 298 GIYDPETGRFTCAIRGAYFFTYHITVFSRNVKVVLMKNGQRVIYTMDSYQGGEDQASGGT 295 SDYNPVTGKFTCKFSGVYYFTYHITVYSRNVRVALVKNGI KMLHTMDGYQGAEDQASGAA 293 NHYDPATGKFTCNVSGVYYFTYHITVYSRNVRVALVKNG IKMLHTVDKYQGAEDQASGGA 291 XHYNVATGKFTCHVAGVYYFTYHITVFSRNVQVSLVKNGVKVLHTKDSYMSSEDQASGGI 291

VLHLDIGDKVWLQVVGGELYNGLFADEDDDTTFSGFLIFDT-------- 336 VLHLDVGDKVWLQVAGGELFNGLFADEDDDTTFSGFLIFGA-------- 336 88.10\% VLNLDVGDKVWLQVTGGELYNGLFADEDDDTTFSGFLIFGA-- - $-339 \quad 100.0 \%$ VLHLEVGDKVWLQVTGGELFNGLYADEDDDTTFTGFLIFGP--_-- $332 \quad 78.61 \%$ VLHLEMGDKVWLQVAGGELFNGLFADEDDDTTFSGFLIFAD-- - $339 \quad 78.76 \%$ VLNLEVGDKVWLQVAGGDLFNGLFADEDDDTTFTGFIIFGA------ $339 \quad 78.17 \%$ ILQLRAGDEVWLQAHRGETFNGLFADADDDTTFTGFLLFSTSEMLEPTT $342 \quad 55.16 \%$ ILELQVGDQVWLQAHGGEVFNGLLADQDDDTTFTGFLLFSNSETLDPV- $339 \quad 56.93 \%$ VLQLKLGJEVWLQVTGGERFNGLFADEDDDTTFTGFLLFSSP--- - 333 - $39.16 \%$ VQELKLGDEVWWQVTGGERFNGLFADEDDDTTFTGFLLFSSS--- -333 $* \quad * * \cdot * * \cdot * \quad ; * * * * * * * * * * * * * * \cdot *$ DQ--GEIGPVGQTGNDGHKGDKGEAGTVGPAGLKGKRGDNGERGPPGKMGPQGVQGPIGL 115 KGNKGELGLPGPLGPKGDLGPLGREGPQGD IGLQGERGIQGPLGPPGKPGPKGDIGVPGS 178 NHYDPQTGRFTCSAAGAYFFTYYITVFSRNVKVALVKNGVRIVHTTDTYQSSEDQAAGGA 295 AHYDTAAGKFTCHIAGVYYFTYHITVFSRNVQVSLVKNGVKILHTKDAYMSSEDQASGGI 291 
Table 2 Amino acids identities in the full and globular domains of Epinephelus coioides Ctrp9 compared to other species.

\begin{tabular}{|c|c|c|}
\hline & Full (\%) & Globular domain (\%) \\
\hline Dicentrarchus labrax & 88.10 & 90.44 \\
\hline Larimichthys crocea & 86.90 & 90.44 \\
\hline Oreochromis niloticus & 83.19 & 91.18 \\
\hline Cynoglossus semilaevis & 78.76 & 83.09 \\
\hline Takifugu rubripes & 78.61 & 86.03 \\
\hline Oryzias latipes & 78.17 & 83.09 \\
\hline Danio rerio & 65.77 & 67.65 \\
\hline Homo sapiens & 59.16 & 69.85 \\
\hline Mus musculus & 57.36 & 67.65 \\
\hline Alligator sinensis & 56.93 & 66.18 \\
\hline Gallus gallus & 55.16 & 61.76 \\
\hline
\end{tabular}

with their counterparts of other teleosts with high bootstrap values.

\section{Tissue distribution of ctrp9 gene expression}

To examine the expression pattern of ctrp9 in different tissues of grouper, real-time quantitative PCR was performed using cDNA samples prepared from selected tissues. As shown in Fig. 4, gene expression of ctrp9 could be detected at high levels in cerebellum and kidney and to a lesser extent in telencephalon, mesocerebrum and medulla oblongata. The expression was at low levels compared with telencephalon in peripheral tissues except kidney.

\section{Effects of nutritional status on the mRNA expression of ctrp9}

To assess the effects of nutritional status on ctrp9 mRNA levels, the fasting and refeeding experiment was performed. In hypothalamus, the mRNA levels of ctrp 9 have an increased trend in fasted group compared to that in fed group (Fig. 5A). However, the hepatic expression of ctrp9 mRNA decreased significantly after fasting of 7 days and was restored back to the normal levels after refeeding (Fig. 5B). Similarly, the expression of ctrp9 mRNA in muscle has a declined trend in fasted group and rose back to the normal levels after refeeding (Fig. 5D). However, refeeding did not raise the expression of ctrp9 mRNA in adipose tissue to the normal levels (Fig. 5C).

\section{Recombinant protein expression and purification of the globular Ctrp9}

The pPICZaA-gctrp9 with $6 \times$ HIS expression vector was constructed and transformed into Pichia pastoris X-33 using electroporation according to the Pichia pastoris expression kit. The positive strain was selected, and the expressed protein was verified by SDS-PAGE and Western blotting with HIS primary antibody. As expected, the molecular weight of recombinant gCtrp9 was $15.8 \mathrm{kDa}$ (Fig. 6A and B). The positive strain was cultured for large scale protein expression, and the protein was purified with $\mathrm{Ni}^{+-} \mathrm{NTA}$ resin. The molecular mass and

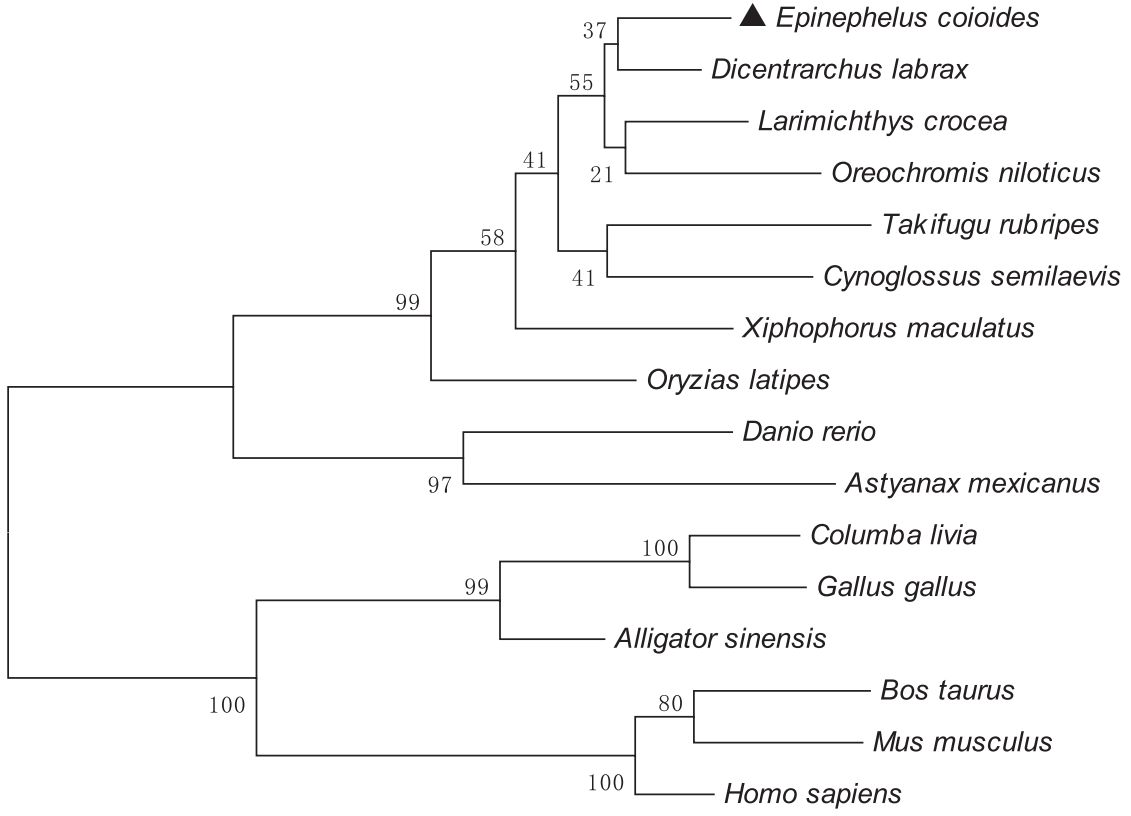

0.1

\section{Figure 3}

Phylogenetic tree based on amino acid alignment for Ctrp9 in different species. Homo sapiens (NP_848635.2), Bos Taurus (XP_005888803.1), Mus musculus (NP_898998.2), Gallus gallus (XP 001234806.2), Columba livia (XP_005501564.1), Alligator sinensis (XP_006017705.1), Danio rerio (XP_005162770.1), Oreochromis niloticus (XP_005471911.1), Takifugu rubripes (XP_003968015.2), Xiphophorus maculates (XP_005797954.1), Astyanax mexicanus (XP_007249048.1), Oryzias latipes (XP_004081095.1), Larimichthys crocea (XP_010736742.1), Dicentrarchus labrax (embICBN81948.1), Cynoglossus semilaevis (XP_008306029.1). http://jme.endocrinology-journals.org DOI: 10.1530/JME-16-0171
() 2017 Society for Endocrinology Printed in Great Britain 


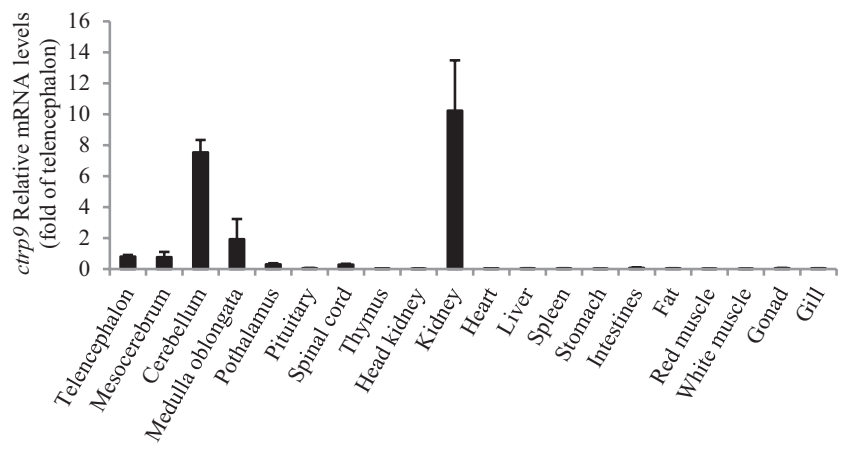

Figure 4

The mRNA expressions of ctrp9 in various tissues of groupers. The mRNA levels were quantified by real-time PCR and normalized against $18 \mathrm{~S}$ transcripts. The values represent the fold of telencephalon. All data were represented as the mean \pm S.E.M. $(n=3)$.

purity of recombinant gCtrp9 were verified by SDS-PAGE and stained by Coomassie Brilliant Blue R250, which exhibited a single protein band, and the purity was over 95\% (Fig. 6C). To further confirm the authenticity of recombinant gCtrp9, mass spectrometry assays of gCtrp9 were performed to obtain sequence information. Sequences of Ctrp9 were introduced into MS BLAS program, which demonstrated that these sequences corresponded to gCtrp9 (see Supplementary Fig. 2).

\section{Effects of gCTRP9 on glucose production in hepatocytes of grouper}

As shown in Fig. 7, when the primary hepatocytes of groupers were treated with recombinant gCtrp9 of $10 \mu \mathrm{g} / \mathrm{mL}$, the glucose concentration in the culture medium showed a slight decrease after 6-h treatment. Furthermore, after 12 -h treatment, the glucose production level decreased significantly (Fig. 7).
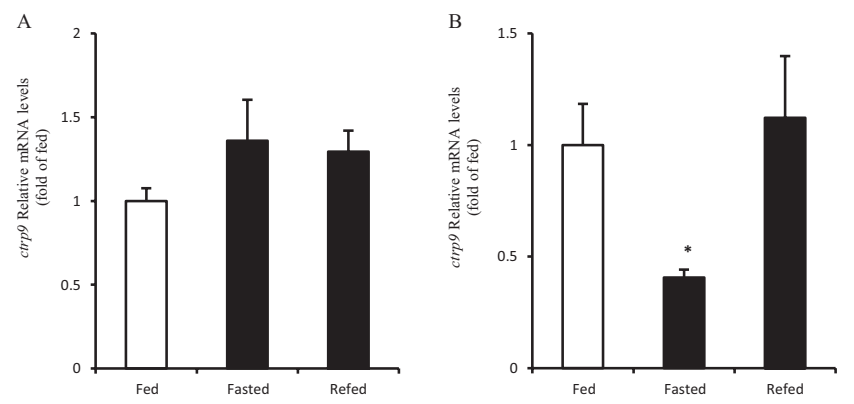

Effects of gCtrp9 on orexigenic/anorexigenic factors and metabolism via i.p. injection

During in vivo experiments, the recombinant gCtrp9 was injected intraperitoneally into groupers. The result showed that both low $(0.5 \mu \mathrm{g} / \mathrm{g}$ B.W. $)$ and high doses $(5 \mu \mathrm{g} / \mathrm{g}$ B.W. $)$ of gCtrp9 could significantly suppress the mRNA expression of $n p y$ and orexin $3 \mathrm{~h}$ after injection. Six hours after injection, high dose of gCtrp9 significantly reduced the mRNA expression of $n p y$ and orexin. Only $n p y$ mRNA expression was suppressed by a low dose of gCtrp9 (Fig. 8A and B). For anorexigenic factors, crh mRNA expression increased significantly after being treated with a high dose of gCtrp9 for $6 \mathrm{~h}$ and $12 \mathrm{~h}$ but was stimulated by the treatment with low dose for $6 \mathrm{~h}$ only. Pomc mRNA expression was remarkably promoted by both low and high doses of gCtrp9 $12 \mathrm{~h}$ after injection (Fig. 8C and D). The serum concentrations of GLU, TG, HDL-C and LDL-C were different among different treatment groups. Twelve hours after injection, the concentrations of serum LDL-C was decreased in both low- and high-dose groups, whereas the concentrations of GLU was only decreased in the lowdose group (Fig. 8E and $\mathrm{H}$ ). The concentration of TG was decreased in high-dose group but maintained at a low level in low-dose group throughout the 12-h treatment (Fig. 8F). On the contrary, the concentration of HDL-C was increased in the low-dose groups with 3-h and 12-h treatment (Fig. 8G).

\section{Discussion}

As CTRP9 was first reported in 2009 (Wong et al. 2009), the functions of CTRP9 were well investigated in mammals. As the paralog of adiponectin, the studies of CTRP9 were focused on fat metabolism, immunization and diabetes mellitus (Su et al. 2012, Peterson et al. 2013, Jung et al.
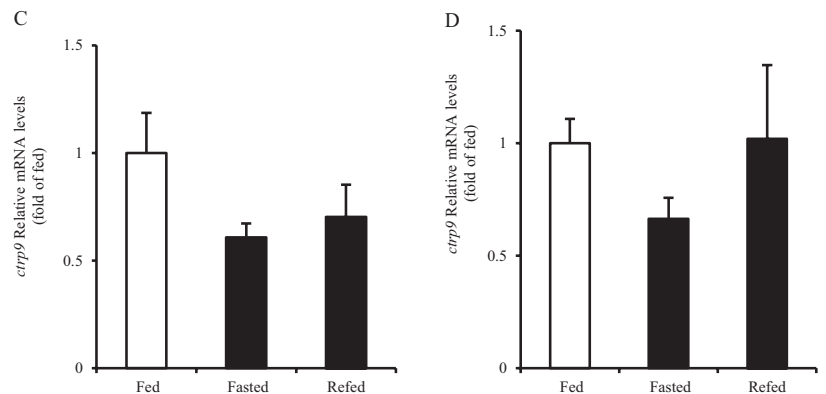

Figure 5

Effects of fasting and refeeding on the mRNA expressions of ctrp9. The mRNA expression levels of ctrp9 in the (A) hypothalamus, (B) liver, (C) adipose tissue and (D) muscle of groupers were quantified by real-time PCR and normalized against $18 \mathrm{~S}$ transcripts. The results were represented as the fold of fed. All data are shown as mean \pm S.E.M. $(n=5-6)$. Significant differences $(P<0.05)$ were indicated by *.

http://jme.endocrinology-journals.org DOI: 10.1530/JME-16-0171
(C) 2017 Society for Endocrinology Printed in Great Britain
Published by Bioscientifica Ltd 


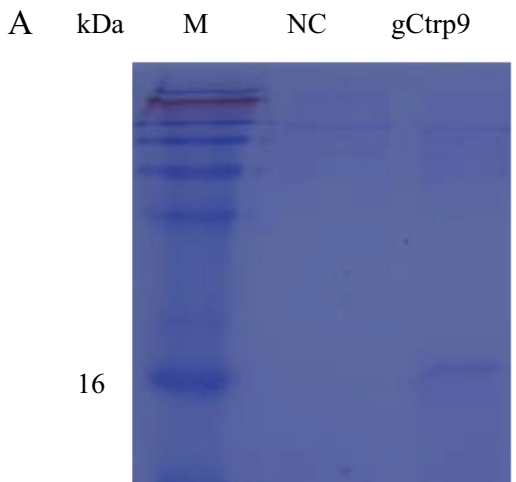

B $\mathrm{kD}$

gCtrp9 NC

C

kDa M gCtrp9

16

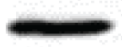

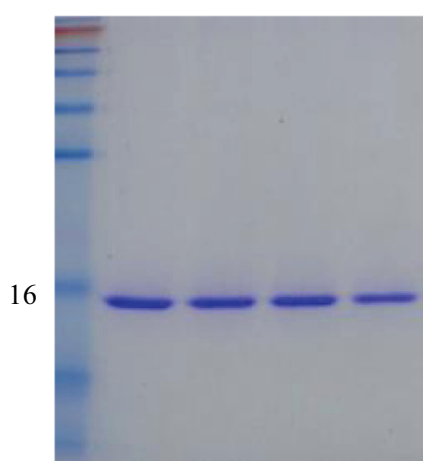

\section{Figure 6}

gCtrp9 expression strain was selected and gCtrp9 protein was expressed. Positive strain was selected and the expressed protein was verified by SDS-PAGE and Western blotting with HIS primary antibody. (A) SDS-PAGE, (B) WB with HIS primary antibody and (C) gCtrp9 protein purified with Ni+-NTA resin was verified by SDS-PAGE.

2014). To clarify the functional roles of Ctrp9 in teleost, firstly, we isolated and characterized the ctrp9 gene from the orange-spotted grouper. The recombinant gCtrp9 protein was obtained by using Pichia pastoris system, and the role of Ctrp9 was evaluated in vivo and in vitro.

The size of human CTRP9 gene was $12.6 \mathrm{~kb}$. It contains four exons and was located on chromosome 13q12.12 (Wong et al. 2009). There were two isoforms of CTRP9 (CTRP9 A and CTRP9 B) in human and primates. Although the identity of two isoforms of CTRP9 was 98\% in humans, they were encoded by different genes and had

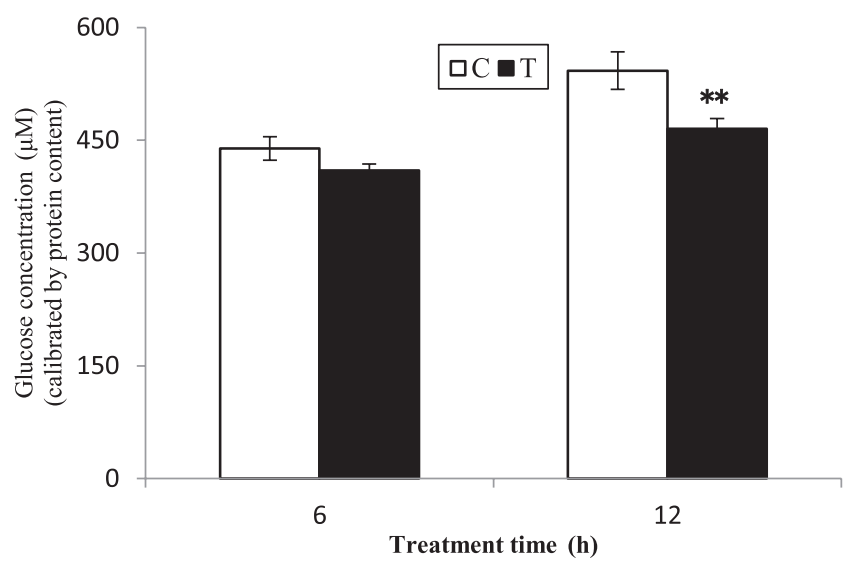

Figure 7

Effect of gCtrp9 on glucose production of grouper primary hepatocytes. The cells were seeded in 24-well plates at $5 \times 10^{5}$ per well in $1 \mathrm{~mL} \mathrm{L15}$ with $10 \% \mathrm{FBS}$. After $4 \mathrm{~h}$, cells were incubated overnight in L15 without phenol red and FBS. The next day, experiments were performed by the addition of vehicle (PBS) or recombinant grouper gCtrp9 protein $(10 \mu \mathrm{g} / \mathrm{mL})$ for the indicated lengths of time. The medium was taken from each sample for the measurement of glucose concentration. Glucose concentration was corrected for protein content in each sample. All data are shown as mean \pm s.E.M. $(n=5-6)$. Significant differences at the $P<0.01$ level are indicated by ** different functions (Peterson et al. 2009). One isoform of ctrp9 gene was isolated and characterized in our study, and the protein structure of Ctrp9 was similar to that of mammals, containing four domains: an N-terminal signal peptide, a short variable domain, a collagen domain and a C-terminal globular domain. 57 Gly-X-Y repeat elements were identified in grouper Ctrp9 protein and a predicted $\mathrm{N}$-glycosylation site was located on the collagen domain. Moreover, a number of phosphorylation sites were predicted in the grouper Ctrp9 protein. All of these were the vital sites in the multiple post-translational modifications. The modifications are indispensable processes in which prolines were hydroxylated and lysines were hydroxylated and glycosylated in the collagen domain (Wong et al. 2009). The Gly-X-Y repeat elements were the characteristic structures that formed a triple helical structure (Khoshnoodi et al. 2006). It was demonstrated that CTRP9 and adiponectin associated via their globular domain, and this process did not require their $\mathrm{N}$-terminal cysteines or their collagen domains (Wong et al. 2009). Cysteines were distributed in the N-terminal domain, which was in line with the results of mammals (Wong et al. 2009). In the present study, the cysteines were found to be distributed in collagen and globular domains of grouper Ctrp9. Sequence alignment at the protein level reveals that the grouper Ctrp9 precursor displayed a high degree of identity with those of other fish. For example, the identity of Ctrp9 precursor between groupers with perches, large yellow croaker and tilapia are 88.1, 86.9 and 83.1\%, respectively. Phylogenetic analysis based on amino acid sequences has confirmed that grouper Ctrp9 could be grouped in the clade of teleosts. Based on those analyses of amino acid sequences, the sequence we obtained is the prospective ctrp9 of grouper.

Published by Bioscientifica Ltd. 

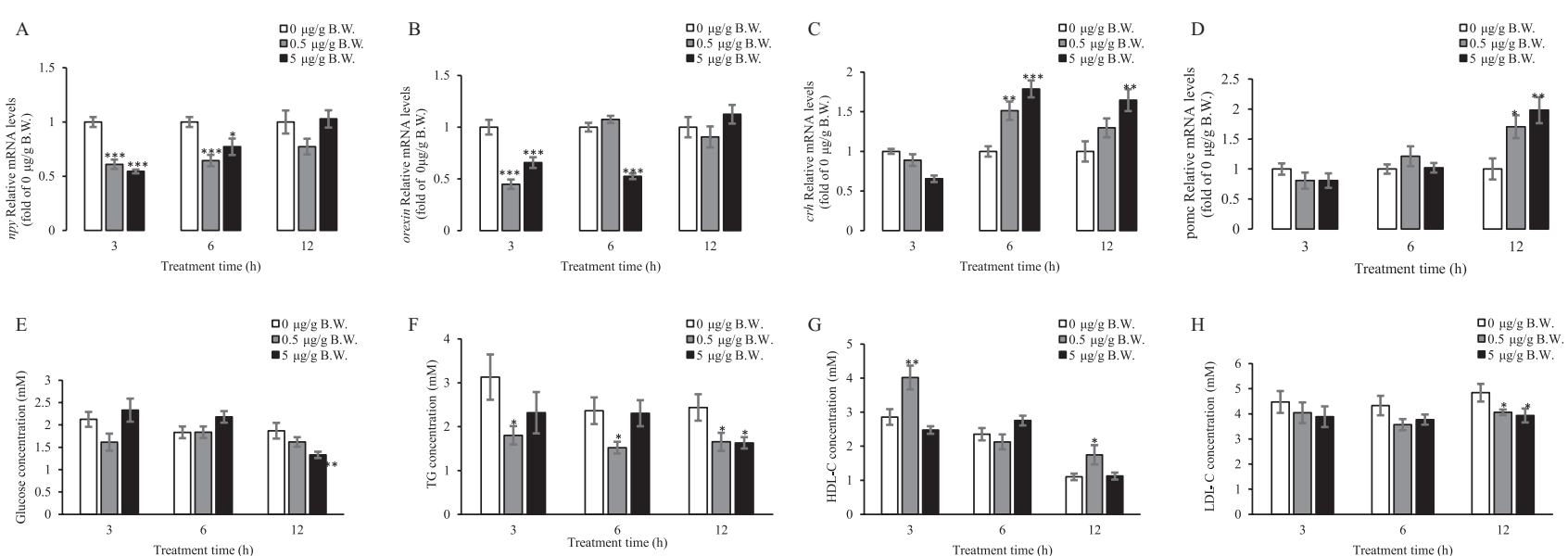

Figure 8

Effects of i.p. injection of recombinant grouper gCtrp9 on the mRNA expression of npy (A), orexin (B), crh (C), pomc (D) in the hypothalamus and the concentration of glucose (E), TG (F), HDL-C (G), LDL-C (H) in serum of grouper. Fish were injected intraperitoneally with vehicle (PBS) or recombinant gCtrp9 $(0.5 \mu \mathrm{g} / \mathrm{g}$ B.W., $5 \mu \mathrm{g} / \mathrm{g}$ B.W.) for the indicated duration of time (3, 6 or $12 \mathrm{~h}$ after i.p. injection). Fish were killed and the hypothalamus was collected for RNA extraction and RT-PCR. The mRNA expression was determined by real-time PCR. The 18S rRNA acts as an internal control. The GLU, TG, HDL-C and LDL-C concentrations were measured with commercial kits according to manufacturer's protocol. The data are presented as mean \pm S.E.M. $(n=8-10)$. The statistical differences were estimated using one-way ANOVA followed by Duncan (D)'s multiple range test (* $P<0.05, * * P<0.01$ and $* * * P<0.001)$.

Adiponectin was mainly expressed in adipose tissue of mammals (Arita et al. 1999). However, the highest mRNA expression of adiponectin was found in red muscle tissue of rainbow trout (Sanchez-Gurmaches et al. 2012). There were two isoforms of adiponectin in zebrafish. Adiponectin $A$ was mainly expressed in kidney, whereas adiponectin $B$ was primarily expressed in the liver and brain regions and slightly in adipose tissue (Nishio et al. 2008). Similarly, Ctrp9 mRNA was detected in adipose tissue, and the expression level of Ctrp9 mRNA in female mice was higher than that of male mice (Wong et al. 2009). However, recent research indicated that Ctrp9 mRNA was predominantly expressed in heart, at the level of 2.5-fold higher than that of adipose tissue (Yuan et al. 2015). Our study showed that ctrp9 mRNA was highly expressed in the cerebellum and kidney. As it is well documented that the major functions of fish kidney are osmotic stress regulation and excretion, we speculated that Ctrp9 may play roles in regulating osmotic stress and excretion in groupers.

As the eukaryotic expression system, P. pastoris has multiple advantages over bacterial systems such as eukaryotic post-translational modifications (Thor et al. 2005, Terpe 2006). Li tried to use P. pastoris expression system to express the recombinant protein of human fCTRP2 (full-length CTRP2), but this recombinant hCTRP2 was found to be unstable and easily degraded in the strains of both X-33 and GS-115. This degradation phenomenon in $P$. pastoris was causally associated with the members of Yapsin family (Li et al. 2011). Several studies reported that the members of Yapsin family can recognize not only the neighboring dibasic amino acid residues but also two basic amino acid residues separated by a given distance and degenerate them (Ledgerwood et al. 1996, Terpe 2006). In our study, several degradation sites that can be recognized by Yapsin protease were located on the collagen domain of grouper mature Ctrp9 protein. The latest study showed that gCTRP9 was the main activated form (Yuan et al. 2015). For these reasons, $P$. pastoris expression system was used to produce the recombinant protein of gCtrp9. We succeed to obtain a recombinant protein with the molecular weight of $15.8 \mathrm{kDa}$. The results of Western blotting and mass spectrometry confirmed that the protein we obtained is the globular domain of grouper Ctrp9.

To evaluate whether Ctrp9 is involved in the control of energy balance and food intake in grouper, the fasting and refeeding experiment was performed. In the fasting and refeeding experiment, expression levels of ctrp9 mRNA were detected in liver, muscle, hypothalamus and adipose tissue. Hypothalamus is an important area in the regulation of feeding. After fasting for 7 days, the ctrp9 mRNA expression was upregulated in the hypothalamus, implying that Ctrp9 could involve in food intake in groupers. This result is consistent with that in mice, in that case, CTRP9 was found to be involved in food intake (Wei et al. 2014). As an anorexigenic factor, CTRP9 could regulate food intake and expression of orexigenic neuropeptides in hypothalamus (Wei et al. 2014). In the present study, ctrp9 mRNA expression was downregulated in the liver, muscle

Published by Bioscientifica Ltd 
and adipose tissue after fasting. As an important endocrine factor which protected from metabolic dysfunction (Peterson et al. 2013), CTRP9 acted as a regulator when the energy was unbalanced. In mammals, the liver can regulate the content of plasma glucose by storing and secreting actions (Moore et al. 2012). In the present study, the glucose production was reduced when hepatocytes were treated with gCtrp9 for $12 \mathrm{~h}$. This result was in agreement with in vivo studies of mammals in which glucose level was suppressed by CTRP9. Serum glucose levels were significantly lowered in Ctrp9-overexpressing mice (Wong et al. 2009, Li et al. 2015). Ctrp9 transgenic mice had markedly reduced plasma glucose levels compared to that in littermate controls (Peterson et al. 2013). Moreover, adiponectin and CTRP3 reduced glucose production from hepatocytes by inhibiting gluconeogenesis (Pajvani \& Scherer 2003, Peterson et al. 2010). These results, taken together, suggested that CTRP9 was involved in the regulation of energy balance.

To investigate the roles of gCtrp9 on the metabolism and regulation of mRNA expression of orexigenic/anorexigenic factors in groupers, i.p. injection experiment was performed. Our results showed that the mRNA expression of orexigenic factors (npy and orexin) were decreased, but those of anorexigenic genes (pomc and $c r h$ ) were increased. Previous study showed that the expression of Npy and Agrp were promoted in hypothalamus in Ctrp9-KO mice, but CTRP9 showed no effect on the gene expression of Pomc in mice (Wei et al. 2014). Similarly, intracerebroventricular injection of adiponectin, a conserved paralog of CTRP9, increased the expression of Crh (Qi et al. 2004). A study showed that Ctrp9 transgenic mice are lean and resist HFDinduced obesity by decreasing food intake (Peterson et al. 2013). Ctrp9-KO mice are fat, which is due to increased food intake (Wei et al. 2014). Moreover, results from both mouse models implicated that CTRP9 was involved in food intake modulation. In the present study, mRNA expression of orexigenic factors was decreased, whereas the anorexigenic genes expression were increased when Ctrp9 was introduced into groupers by i.p. injection. These results indicated that Ctrp9 could regulate the expression of genes related food intake. The further study need to be performed to investigate whether Ctrp9 directly regulate feeding in groupers. The results of serum measurement showed that the concentrations of glucose, TG and LDL-C were decreased after i.p. injection of gCtrp9. These results were similar to the study on Ctrp9-Tg mice in which the serum glucose and TG content were downregulated in comparison with control groups (Peterson et al. 2013). Adenovirus- or lentiviral-mediated overexpression of Ctrp 9 in mice also significantly lowered serum glucose levels
(Wong et al. 2009, Li et al. 2015). This result was consistent with that we got from the in vitro experiment. A previous study in mice demonstrated that CTRP9 could suppress HFD-induced TG accumulation (Jung et al. 2015). A study in 3T3-L1 adipocytes showed that TG content was decreased in gAd-treated adipocytes compared to that in untreated cells (Lazra et al. 2015). Furthermore, serum TG levels were significantly decreased in gAd-Tg mice (Yamauchi et al. 2003). These results suggested that CTRP9 or adiponectin could regulate the serum content of TG. HDL participated in the initiation of reverse cholesterol transport, which was the key antiatherogenic action (Lee-Rueckert et al. 2016). Studies have showed that the concentration of CTRP9 was positively associated with HDL-C in the serum of mammal (Jung et al. 2014, Wang et al. 2015b). In addition, a similar result reported that adiponectin was positively associated with HDL-C in human serum (Katsiki et al. 2011, Lubkowska et al. 2015). Interestingly, in our study, gCtrp9 was found to upregulate the content of HDL-C in the serum of groupers. Based on these results, we speculated that Ctrp9 might play a role in cholesterol metabolic process by regulating the content of HDL-C. Our result showed that the LDL-C content was decreased in gCtrp9 injection groups. Similar to our findings, Wang's study suggested an inverse correlation between serum CTRP9 and LDL-C (Wang et al. 2015b). A study in human showed that adiponectin was negatively associated with LDL-C (Bansal et al. 2006). These results suggested that CTRP9 or adiponectin could regulate the serum content of LDL-C. Results of our in vivo study showed that effects of gCtrp9 on Glu, TG and LDL-C contents have no coincident trend at 3 or $6 \mathrm{~h}$ after injection. However, at the time point of $12 \mathrm{~h}$ after injection, the contents of Glu, TG and LDL-C were decreased significantly. The possible reason could be that the effect of gCtrp9 on the change of contents of Glu, TG and LDL-C in serum is not stable after 3-h or 6-h injection. The effects become stabilized when gCtrp9 is acting on the fish $12 \mathrm{~h}$ after injection. Overall, gCtrp9 could play a role in metabolism and involved in regulating the mRNA expression of orexigenic/anorexigeinc factors in groupers.

\section{Conclusions}

In the present study, the full-length cDNA of grouper ctrp9 was isolated and characterized. The mRNA expression of ctrp9 could be detected at high levels in cerebellum and kidney of groupers. Using the recombinant protein of gCtrp9 produced from Pichia pastoris, we firstly found that Ctrp9 may take part in the regulation of energy metabolism

Published by Bioscientifica Ltd 
and food intake in teleost. Our further research will focus on exploring the underlying mechanism related to the Ctrp9 in the regulation of energy metabolism and food intake.

\section{Supplementary data}

This is linked to the online version of the paper at http://dx.doi.org/10.1530/ JME-16-0171.

\section{Declaration of interest}

The authors declare that there is no conflict of interest that could be perceived as prejudicing the impartiality of the research reported.

\section{Funding}

This work did not receive any specific grant from any funding agency in the public, commercial, or not-for-profit sector.

\section{Acknowledgements}

This work was supported by the National Science Foundation of China (31272639 and 31472259), the Guangdong Provincial Science and Technology Program (2015A020216006), Guangdong Oceanic and Fishery Program (A201601C02), the Developmental Funds for Strategic Emerging Industries of Shen Zhen (NYSW20140401010064) and Modern Agriculture Talents Support Program (2016-2020) to Dr Wensheng Li.

\section{References}

Arita Y, Kihara S, Ouchi N, Takahashi M, Maeda K, Miyagawa J, Hotta K, Shimomura I, Nakamura T, Miyaoka K, et al. 1999 Paradoxical decrease of an adipose-specific protein, adiponectin, in obesity. Biochemical and Biophysical Research Communications 257 79-83. (doi:10.1006/bbrc.1999.0255)

Bansal N, Charlton-Menys V, Pemberton P, McElduff P, Oldroyd J, Vyas A, Koudsi A, Clayton PE, Cruickshank JK \& Durrington PN 2006 Adiponectin in umbilical cord blood is inversely related to low-density lipoprotein cholesterol but not ethnicity. Journal of Clinical Endocrinology and Metabolism 91 2244-2249. (doi:10.1210/jc.2005-2714)

Byerly MS, Petersen PS, Ramamurthy S, Seldin MM, Lei X, Provost E, Wei ZK, Ronnett GV \& Wong GW 2014 C1q/TNF-related protein 4 (CTRP4) is a unique secreted protein with two tandem C1q domains that functions in the hypothalamus to modulate food intake and body weight. Journal of Biological Chemistry 289 4055-4069. (doi:10.1074/jbc.M113.506956)

Chen J, Zhang Y, Tang Z, Mao J, Kuang Z, Qin C \& Li W 2012 Production of recombinant orange-spotted grouper (Epinephelus coioides) folliclestimulating hormone (FSH) in single-chain form and dimer form by Pichia pastoris and their biological activities. General and Comparative Endocrinology 178 237-249. (doi:10.1016/j.ygcen.2012.05.009)

Esfahani M, Movahedian A, Baranchi M \& Goodarzi MT 2015 Adiponectin: an adipokine with protective features against metabolic syndrome. Iranian Journal of Basic Medical Sciences 18 430-442.

Jung CH, Lee MJ, Kang YM, Jang JE, Leem J, Lee YL, Seol SM, Yoon HK, Lee WJ \& Park JY 2014 Association of serum C1q/TNF-related protein-9 concentration with arterial stiffness in subjects with type 2 diabetes. Journal of Clinical Endocrinology and Metabolism 99 E2477-E2484. (doi:10.1210/jc.2014-2524)

Jung TW, Hong HC, Hwang HJ, Yoo HJ, Baik SH \& Choi KM 2015 C1q/ TNF-Related Protein 9 (CTRP9) attenuates hepatic steatosis via the autophagy-mediated inhibition of endoplasmic reticulum stress. Molecular and Cellular Endocrinology 417 131-140. (doi:10.1016/j. mce.2015.09.027)
Kadowaki T, Yamauchi T, Kubota N, Hara K, Ueki K \& Tobe K 2006 Adiponectin and adiponectin receptors in insulin resistance, diabetes, and the metabolic syndrome. Journal of Clinical Investigation 116 1784-1792. (doi:10.1172/JCI29126)

Kambara T, Ohashi K, Shibata R, Ogura Y, Maruyama S, Enomoto T, Uemura Y, Shimizu Y, Yuasa D, Matsuo K, et al. 2012 CTRP9 protein protects against myocardial injury following ischemia-reperfusion through AMP-activated protein kinase (AMPK)-dependent mechanism. Journal of Biological Chemistry 287 18965-18973. (doi:10.1074/jbc.M112.357939)

Kambara T, Shibata R, Ohashi K, Matsuo K, Hiramatsu-Ito M, Enomoto T, Yuasa D, Ito M, Hayakawa S, Ogawa H, et al. 2015 C1q/tumor necrosis factor-related protein 9 protects against acute myocardial injury through an adiponectin receptor I-AMPK-dependent mechanism. Molecular and Cellular Biology 35 2173-2185. (doi:10.1128/MCB.01518-14)

Katsiki N, Mikhailidis DP, Gotzamani-Psarrakou A, Yovos JG \& Karamitsos D 2011 Effect of various treatments on leptin, adiponectin, ghrelin and neuropeptide $\mathrm{Y}$ in patients with type 2 diabetes mellitus. Expert Opinion on Therapeutic Targets 15 401-420. (doi:10.1517/14728222.2011.553609)

Khoshnoodi J, Cartailler JP, Alvares K, Veis A \& Hudson BG 2006 Molecular recognition in the assembly of collagens: terminal noncollagenous domains are key recognition modules in the formation of triple helical protomers. Journal of Biological Chemistry 281 38117-38121. (doi:10.1074/jbc.R600025200)

Lazra Y, Falach A, Frenkel L, Rozenberg K, Sampson S \& Rosenzweig T 2015 Autocrine/paracrine function of globular adiponectin: inhibition of lipid metabolism and inflammatory response in 3T3-L1 adipocytes. Journal of Cellular Biochemistry 116 754-766. (doi:10.1002/jcb.25031)

Ledgerwood EC, Brennan SO, Cawley NX, Loh YP \& George PM 1996 Yeast aspartic protease 3 (Yap3) prefers substrates with basic residues in the P2, P1 and P2' positions. FEBS Letters 383 67-71. (doi:10.1016/0014-5793(96)00219-0)

Lee-Rueckert M, Escola-Gil JC \& Kovanen PT 2016 HDL functionality in reverse cholesterol transport - challenges in translating data emerging from mouse models to human disease. Biochimica et Biophysica Acta 1861 566-583. (doi:10.1016/j.bbalip.2016.03.004)

Li H, Gao X, Zhou Y, Li N, Ge C, Hui X, Wang Y, Xu A, Jin S \& Wu D 2011 High level expression, purification and characterization of active fusion human $\mathrm{C} 1 \mathrm{q}$ and tumor necrosis factor related protein 2 (hCTRP2) in Escherichia coli. Protein Expression and Purification 79 1-6. (doi:10.1016/j.pep.2011.03.013)

Li J, Zhang P, Li T, Liu Y, Zhu Q, Chen T, Liu T, Huang C, Zhang J, Zhang Y, et al. 2015 CTRP9 enhances carotid plaque stability by reducing pro-inflammatory cytokines in macrophages. Biochemical and Biophysical Research Communications 458 890-895. (doi:10.1016/j.bbrc.2015.02.054)

Lubkowska A, Radecka A, Bryczkowska I, Rotter I, Laszczynska M \& Dudzinska W 2015 Serum adiponectin and leptin concentrations in relation to body fat distribution, hematological indices and lipid profile in humans. International Journal of Environmental Research and Public Health 12 11528-11548. (doi:10.3390/ijerph120911528)

Moore MC, Coate KC, Winnick JJ, An Z \& Cherrington AD 2012 Regulation of hepatic glucose uptake and storage in vivo. Advances in Nutrition 3 286-294. (doi:10.3945/an.112.002089)

Nishio S, Gibert Y, Bernard L, Brunet F, Triqueneaux G \& Laudet V 2008 Adiponectin and adiponectin receptor genes are coexpressed during zebrafish embryogenesis and regulated by food deprivation. Developmental Dynamics 237 1682-1690. (doi:10.1002/dvdy.21559)

Pajvani UB \& Scherer PE 2003 Adiponectin: systemic contributor to insulin sensitivity. Current Diabetes Reports 3 207-213. (doi:10.1007/ s11892-003-0065-2)

Peterson JM, Wei ZK \& Wong W 2009 CTRP8 and CTRP9B are novel proteins that hetero-oligomerize with C1q/TNF family members.

Published by Bioscientifica Ltd. 
Biochemical and Biophysical Research Communications 388 360-365. (doi:10.1016/j.bbrc.2009.08.014)

Peterson JM, Wei ZK \& Wong GW 2010 C1q/TNF-related protein-3 (CTRP3), a novel adipokine that regulates hepatic glucose output. Journal of Biological Chemistry 285 39691-39701. (doi:10.1074/jbc. M110.180695)

Peterson JM, Aja S, Wei ZK \& Wong GW 2012 CTRP1 protein enhances fatty acid oxidation via AMP-activated protein kinase (AMPK) activation and acetyl-CoA carboxylase (ACC) inhibition. Journal of Biological Chemistry 287 1576-1587. (doi:10.1074/jbc.M111.278333)

Peterson JM, Wei Z, Seldin MM, Byerly MS, Aja S \& Wong GW 2013 CTRP9 transgenic mice are protected from diet-induced obesity and metabolic dysfunction. American Journal of Physiology: Regulatory, Integrative and Comparative Physiology 305 R522-R533. (doi:10.1152/ ajpregu.00110.2013)

Qi Y, Takahashi N, Hileman SM, Patel HR, Berg AH, Pajvani UB, Scherer PE \& Ahima RS 2004 Adiponectin acts in the brain to decrease body weight. Nature Medicine 10 524-529. (doi:10.1038/nm1029)

Qin C, Wang B, Sun C, Jia J \& Li W 2014 Orange-spotted grouper (Epinephelus coioides) adiponectin receptors: molecular characterization, mRNA expression, and subcellular location. General and Comparative Endocrinology 198 47-58. (doi:10.1016/j. ygcen.2013.12.013)

Sanchez-Gurmaches J, Cruz-Garcia L, Gutierrez J \& Navarro I 2012 Adiponectin effects and gene expression in rainbow trout: an in vivo and in vitro approach. Journal of Experimental Biology $\mathbf{2 1 5}$ 1373-1383. (doi:10.1242/jeb.061697)

Schaffler A \& Buechler C 2012 CTRP family: linking immunity to metabolism. Trends in Endocrinology and Metabolism 23 194-204. (doi:10.1016/j.tem.2011.12.003)

Scherer PE 2006 Adipose tissue: from lipid storage compartment to endocrine organ. Diabetes 55 1537-1545. (doi:10.2337/db06-0263)

Schmittgen TD \& Livak KJ 2008 Analyzing real-time PCR data by the comparative C(T) method. Nature Protocols 3 1101-1108. (doi:10.1038/nprot.2008.73)

Seldin MM, Tan SY \& Wong GW 2014 Metabolic function of the CTRP family of hormones. Reviews in Endocrine and Metabolic Disorders 15 111-123. (doi:10.1007/s11154-013-9255-7)

Su H, Yuan YX, Wang XM, Lau WB, Wang YJ, Wang XL, Gao EH, Koch W \& Ma XL 2012 Inhibition of CTRP9, a novel and cardiac-abundantly expressed cell survival molecule, by TNF alpha-initiated oxidative signaling contributes to exacerbated cardiac injury in diabetic mice. Basic Research in Cardiology 108 315. (doi:10.1007/s00395-012-0315-z)

Sun Y, Yi W, Yuan Y, Lau WB, Yi D, Wang X, Wang Y, Su H, Wang X, Gao E, et al. 2013 C1q/tumor necrosis factor-related protein-9, a novel adipocyte-derived cytokine, attenuates adverse remodeling in the ischemic mouse heart via protein kinase A activation. Circulation 128 S113-S120. (doi:10.1161/CIRCULATIONAHA.112.000010)

Terpe K 2006 Overview of bacterial expression systems for heterologous protein production: from molecular and biochemical fundamentals to commercial systems. Applied Microbiology and Biotechnology 72 211-222. (doi:10.1007/s00253-006-0465-8)

Thor D, Xiong S, Orazem CC, Kwan AC, Cregg JM, Lin-Cereghino J \& Lin-Cereghino GP 2005 Cloning and characterization of the Pichia pastoris MET2 gene as a selectable marker. FEMS Yeast Research $\mathbf{5}$ 935-942. (doi:10.1016/j.femsyr.2005.03.009)

Trujillo ME \& Scherer PE 2006 Adipose tissue-derived factors: impact on health and disease. Endocrine Reviews 27 762-778. (doi:10.1210/ er.2006-0033)
Uemura Y, Shibata R, Ohashi K, Enomoto T, Kambara T, Yamamoto T, Ogura Y, Yuasa D, Joki Y, Matsuo K, et al. 2013 Adipose-derived factor CTRP9 attenuates vascular smooth muscle cell proliferation and neointimal formation. FASEB Journal 27 25-33. (doi:10.1096/ fj.12-213744)

Wang B, Qin C, Zhang C, Jia J, Sun C \& Li W 2014 Differential involvement of signaling pathways in the regulation of growth hormone release by somatostatin and growth hormone-releasing hormone in orange-spotted grouper (Epinephelus coioides). Molecular and Cellular Endocrinology 382 851-859. (doi:10.1016/j. mce.2013.10.025)

Wang B, Jia J, Yang G, Qin J, Zhang C, Zhang Q, Sun C \& Li W 2015a In vitro effects of somatostatin on the growth hormone-insulin-like growth factor axis in orange-spotted grouper (Epinephelus coioides) General and Comparative Endocrinology 237 1-9. (doi:10.1016/j. ygcen.2015.10.014)

Wang J, Hang T, Cheng XM, Li DM, Zhang QG, Wang LJ, Peng YP \& Gong JB 2015b Associations of C1q/TNF-related protein-9 levels in serum and epicardial adipose tissue with coronary atherosclerosis in humans. BioMed Research International 2015971683. (doi:10.1155/2015/971683)

Wei Z, Peterson JM \& Wong GW 2011 Metabolic regulation by C1q/TNFrelated protein-13 (CTRP13): activation OF AMP-activated protein kinase and suppression of fatty acid-induced JNK signaling. Journal of Biological Chemistry 286 15652-15665. (doi:10.1074/jbc.M110.201087)

Wei Z, Lei X, Petersen PS, Aja S \& Wong GW 2014 Targeted deletion of C1q/TNF-related protein 9 increases food intake, decreases insulin sensitivity, and promotes hepatic steatosis in mice. American Journal of Physiology: Endocrinology and Metabolism 306 E779-E790. (doi:10.1152/ajpcell.00381.2013)

Wong GW, Krawczyk SA, Kitidis-Mitrokostas C, Revett T, Gimeno R \& Lodish HF 2008 Molecular, biochemical and functional characterizations of C1q/TNF family members: adipose-tissueselective expression patterns, regulation by PPAR-gamma agonist, cysteine-mediated oligomerizations, combinatorial associations and metabolic functions. Biochemical Journal 416 161-177. (doi:10.1042/ BJ20081240)

Wong GW, Krawczyk SA, Kitidis-Mitrokostas C, Ge G, Spooner E, Hug C, Gimeno R \& Lodish HF 2009 Identification and characterization of CTRP9, a novel secreted glycoprotein, from adipose tissue that reduces serum glucose in mice and forms heterotrimers with adiponectin. FASEB Journal 23 241-258. (doi:10.1096/fj.08-114991)

Yamauchi T, Kamon J, Waki H, Imai Y, Shimozawa N, Hioki K, Uchida S, Ito Y, Takakuwa K, Matsui J, et al. 2003 Globular adiponectin protected ob/ob mice from diabetes and ApoE-deficient mice from atherosclerosis. Journal of Biological Chemistry 278 2461-2468. (doi:10.1074/jbc.M209033200)

Yuan Y, Lau WB, Su H, Sun Y, Yi W, Du Y, Christopher T, Lopez B, Wang Y \& Ma XL 2015 C1q-TNF-related protein-9, a novel cardioprotetcive cardiokine, requires proteolytic cleavage to generate a biologically active globular domain isoform. American Journal of Physiology: Endocrinology and Metabolism 308 E891-E898. (doi:10.1152/ ajpendo.00450.2014)

Zheng QJ, Yuan YX, Su H, Yi W, Lau WB, Wang YJ, Wang XL, Sun Y, Lopez B, Christopher T, et al. 2011 C1q/TNF-related proteins (CTRPs), a family of novel adipokines, induce vascular relaxation through the adiponectin receptor-1/AMPK/eNOS/nitric oxide signaling pathway. Arteriosclerosis, Thrombosis, and Vascular Biology 31 2616-2623. (doi:10.1161/ATVBAHA.111.231050)

Received in final form 26 January 2017

Accepted 10 March 2017

Accepted Preprint published online 10 March 2017 http://jme.endocrinology-journals.org

DOI: 10.1530/JME-16-0171
๑) 2017 Society for Endocrinology Printed in Great Britain
Published by Bioscientifica Ltd 